\title{
Prediction of antigenic peptides of Lasiotoxin-2 (LpTX2) from Lasiodora parahybana
}

\author{
Gomase V.S. ${ }^{* 1}$ and Shyamkumar K. \\ ${ }^{* 1}$ Proteomics Unit, Department of Bioinformatics, Padmashree Dr. D. Y. Patil University, Plot No-50, \\ Sector-15, CBD Belapur, Navi Mumbai, 400614, MS, India, Mobile- +91-9987770696, Mail- \\ virusgene1@yahoo.co.in
}

\begin{abstract}
The toxin Lasiotoxin-2 (LpTX2) is a 49aa residue peptide is isolated from the venom of Lasiodora parahybana.In this assay we have predicted the binding affinity of toxin Lasiotoxin-2 (LpTX2) having 49 amino acids, which shows 41 nonamers. Peptide fragments of the neurotoxin can be used to select nonamers for use in rational vaccine design and to increase the understanding of roles of the immune system in neurotoxin studies. Small segment

'11-

KEGKPCKPKGCKCNDKDNKDHKKCS-36' of toxin protein called the antigenic epitopes is sufficient for eliciting the desired immune response. Immunization cassettes should be capable of immunizing of broad immunity against both humoral and cellular epitope thus giving vaccines the maximum ability to deal with neurotoxin protein of Opisthacanthus madagascariensis. Binding ability prediction of antigen peptides to MHC class molecules is important in vaccine development, We also found the SVM based MHCII-IAb peptide regions,26- DKDNKDHKK , 27- KDNKDHKKC , 8CDIKKEGKP , 5- TLECDIKKE , (optimal score is 0.557); MHCII-IAd peptide regions, 32HKKCSGGWR, 9- DIKKEGKPC , 20- KGCKCNDKD 35- CSGGWRCKL , (optimal score is0.363); $\mathrm{MHCll}-\mathrm{IAg} 7$ peptide regions , 13EGKPCKPKG , 3- ECTLECDIK ,37- GGWRCKLKL , 22- CKCNDKDNK, (optimal score is 0.988); and MHCII- RT1.B peptide regions, 1- FFECTLECD , 5TLECDIKKE , 22- CKCNDKDNK , 40- RCKLKLCLK

(optimal score is 0.556) which represented predicted binders from neurotoxin protein. We have predicted a successful immunization.

Key words: Antigen, Epitope, PSSM, SVM, MHC, Peptide vaccine

Abbreviations: Goldman, Engelberg and Steitz, (GES); major histocompatibility complex, (MHC); Position Specific Scoring Matrices, (PSSMs); Support Vector Machine, (SVM)
\end{abstract}

*Correspondence: Virendra S. Gomase, Department of Bioinformatics, Padmashree Dr. D.Y. Patil University, Plot No-50, Sector-15, CBD Belapur, Navi Mumbai, 400614, India; Mobile- +91-9987770696; Mailvirusgene1@yahoo.co.in

\section{Introduction}

\section{Lasiodora parahybana}

The Brazilian salmon pink (Lasiodora parahybana) is a popular species of tarantula kept as pets in the tarantula keeping hobby today. Originating from Brazil (hence the common name), this spider typically grows to a leg span of $20 \mathrm{~cm}$, although occasionally exceptional specimens can reach leg spans of $25 \mathrm{~cm}$. Large females can weigh upwards of 100 grams. In the wild the Brazilian salmon pink tarantula has even been known to prey on the deadly fer-de-lance pit viper snake [1].

\section{Molecular Aspect}

The Lasiodora parahybana species is secreated various types of proteins which devolope body structure and body mechanism, internally or externally. In the NCBI entrez record, there is five types of proteins secreted by this species and one taxonomic link.Lasiotoxine-2 (LpTX2) has been taken in analysis because only this is the one toxin in five others four are precursors. The enzyme expressed by the venom gland which composed of specific tissue, the subcellular location is secreted by cells. This function is toxic to the mice, but not to the insects $[2,3]$.

\section{Methodology}

MHC molecules are cell surface glycoproteins, which take active part in host immune reactions. The involvement of $\mathrm{MHC}$ class molecules in response to almost all antigens and the variable length of interacting peptides make the study of MHC Class molecules very interesting. MHC molecules have been well characterized in terms of their role in immune reactions [4-6]. They bind to some of the peptide fragments generated after proteolytic cleavage of antigen [7]. This binding acts like red flags for antigen specific and to generate immune response against the parent antigen. So a small fragment of antigen can induce immune response against whole antigen. Alpha-toxin BeM10 peptides are most suitable for subunit vaccine development because with single epitope, the immune response can be generated in large population.TAP is a transporter associated with MHC class I restricted antigen processing. The TAP is 
heterodimeric transporter belong to the family of $\mathrm{ABC}$ transporter, that uses the energy provided by ATP to translocate the peptides across the membrane [8]. The subset of this transported peptide will bind MHC class I molecules and stabilize them. These MHCpeptide complexes will be translocated on the surface of antigen presenting cells (APCs). This theme is implemented in designing subunit and synthetic peptide vaccines [9]. One of the important problems in subunit vaccine design is to search antigenic regions in an antigen [10] that can stimulate $T$ cells called T-cell epitopes. T-cell immune responses are triggered by the recognition of foreign peptide antigens bound to cell membrane-expressed major histocompatibility complex (MHC) molecules [11].

\section{Results and Interpretations}

The sequence of protein is 49 amino acids in which include some hydrophilic, some hydrophobic, some are MHC binder protein and some are epitope binding proteins. If we predict the all data of hydrophilic, hydrophobic , epitope binding and MHC class I and II binding proteins, then we easily predict the antigenicity of protein Lasiotoxine -2 from Lasiodora parahybana. The high score of Lasiotoxine -2 is the $0.9,0.8$ and 0.5 of the I$\mathrm{Ag} 7$ allele and residue number is $13,3,37$ and 3 , which bind the sequence is EGKPCKPKG, ECTLECDIK, GGWRCKLKL and CKCNDKDNK (Table-1). The TAP pred prediction tool is useful for the prediction of $\mathrm{MHC}$ class I. This tool function is same as the MHC2pred. This result about Lasiotoxine is the start position is 39, sequence is WRCKLKLCL , score is 8.567 and prediction affinity is high also start position 41, sequence CKLKLCLKF , score 7.027 and prediction affinity is high (Table-2). It was shown that the toxin protein is hydrophobic in nature and contains segments of low complexity and high-predicted flexibility. Predicted antigenic fragments can bind to MHC molecule is the first bottlenecks in vaccine design.

\section{Conclusion}

Lasiodora parahybana involved multiple antigenic components to direct and empower the immune system to protect the host from infection.MHC molecules are cell surface proteins, which take active part in host immune reactions and involvement of $\mathrm{MHC}$ class in response to almost all antigens and it give effects on specific sites. Predicted MHC binding regions acts like red flags for antigen specific and generate immune response against the parent antigen. So a small fragment of antigen can induce immune response against whole antigen. This theme is implemented in designing subunit and synthetic peptide vaccines. The sequence analysis method is allows potential drug targets to identify active sites, which form antibodies against or spider venom infection. The method integrates prediction of peptide MHC class binding; proteosomal $\mathrm{C}$ terminal cleavage and TAP transport efficiency. Antigenic epitopes of Lasiotoxine -2 protein are important antigenic determinants against the various toxic reactions and spider venom infections.

\section{References}

1. Stanley A. Schultz Marguerite J. Schultz, Tarantula Keeper's Guide (1998),Barron's Educational Series Inc., U.S. Page 127.

2. Santos PS, Schinemann JA, Gabardo J, Bicalho Mda G. New evidence that the MHC influences odor perception in humans: a study with 58 Southern Brazilian students. Horm Behav. 2005 Apr;47(4):384-8.

3. Escoubas P., Celerier M.-L., Romi-Lebrun R., Nakajima T. Two novel peptide neurotoxins from the venom of the tarantula Lasiodora parahybana. Toxicon 35:805-806, 1996.

4. Singh, H. and Raghava, G. P. S. Biotech Software and Internet Report, 3:146) (2002)

5. Bhasin, M., Singh, H., and Raghava, G.P.S. MHCBN: A comprehensive database of MHC binding and non-binding peptides. Bioinformatics 19: 666-667. 2003.

6. Cui J, Han LY, Lin HH, Tang ZQ, Jiang L, Cao $Z W$, Chen YZ. MHC-BPS: MHC-binder prediction server for identifying peptides of flexible lengths from sequence-derived physicochemical properties. Immunogenetics. 2006 Aug;58(8):607-13. Epub 2006 Jul 11.

7. Kumar M, Gromiha MM, Raghava GP. Identification of DNA-binding proteins using support vector machines and evolutionary profiles.BMC Bioinformatics. 2007 Nov 27;8(1):463

8. Manoj Bhasin and G.P.S. Raghava Analysis and prediction of affinity of TAP binding peptides using cascade SVM, Protein Science (2004), 13:596-607.

9. Gomase V.S., Kale K.V., Chikhale N.J., Changbhale S.S. Prediction of MHC Binding Peptides and Epitopes from Alfalfa mosaic virus. Curr. Drug Discov. Technol. 2007 Jun; 4(2):1171215.

10. Schirle, M., Weinschenk, T. and Stevanovic, S. (2001) Combining computer algorithms with experimental approaches permits the rapid and accurate identification of $T$ cell epitopes from 
defined antigens. J Immunol Methods, 257, 116.

11. Margulies, D.H. 1997. Interactions of TCRs with MHC-peptide complexes: a quantitative basis for mechanistic models. Curr Opin Immunol 9:390395. 
TABLE 1:- MHC class II binding peptide nonamers from toxin Lasiotoxine-2 (LpTX2) Protein.

\begin{tabular}{|l|l|l|c|c|}
\hline $\begin{array}{l}\text { MHC } \\
\text { ALLELE }\end{array}$ & Rank & Sequence & $\begin{array}{l}\text { Residue } \\
\text { No. }\end{array}$ & $\begin{array}{l}\text { Peptide } \\
\text { Score }\end{array}$ \\
\hline I-Ab & 1 & DKDNKDHKK & 26 & 0.557 \\
\hline I-Ab & 2 & KDNKDHKKC & 27 & 0.406 \\
\hline I-Ab & 3 & CDIKKEGKP & 8 & 0.265 \\
\hline I-Ab & 4 & TLECDIKKE & 5 & 0.263 \\
\hline I-Ad & 1 & HKKCSGGWR & 32 & 0.363 \\
\hline I-Ad & 2 & DIKKEGKPC & 9 & 0.251 \\
\hline I-Ad & 3 & KGCKCNDKD & 20 & 0.201 \\
\hline I-Ad & 4 & CSGGWRCKL & 35 & 0.171 \\
\hline I-Ag7 & 1 & EGKPCKPKG & 13 & 0.988 \\
\hline I-Ag7 & 2 & ECTLECDIK & 3 & 0.939 \\
\hline I-Ag7 & 3 & GGWRCKLKL & 37 & 0.835 \\
\hline I-Ag7 & 4 & CKCNDKDNK & 22 & 0.829 \\
\hline RT1.B & 1 & FFECTLECD & 1 & 0.556 \\
\hline RT1.B & 2 & TLECDIKKE & 5 & -0.043 \\
\hline RT1.B & 3 & CKCNDKDNK & 22 & -0.130 \\
\hline RT1.B & 4 & RCKLKLCLK & 40 & -0.133 \\
\hline
\end{tabular}

TABLE 2 :- TAP Peptide binder of Lasiotoxine-2 (LpTX2) Protein

\begin{tabular}{|l|l|l|l|l|}
\hline $\begin{array}{l}\text { Peptide } \\
\text { Rank }\end{array}$ & $\begin{array}{l}\text { Start } \\
\text { Position }\end{array}$ & Sequence & Score & Predicted Affinity \\
\hline 1 & 39 & WRCKLKLCL & 8.567 & High \\
\hline 2 & 41 & CKLKLCLKF & 7.027 & High \\
\hline 3 & 35 & CSGGWRCKL & 5.366 & Intermediate \\
\hline 4 & 33 & KKCSGGWRC & 5.186 & Intermediate \\
\hline 5 & 28 & DNKDHKKCS & 4.753 & Intermediate \\
\hline 6 & 37 & GGWRCKLKL & 4.567 & Intermediate \\
\hline 7 & 12 & KEGKPCKPK & 4.449 & Intermediate \\
\hline 8 & 10 & IKKEGKPCK & 4.339 & Intermediate \\
\hline 9 & 34 & KCSGGWRCK & 4.246 & Intermediate \\
\hline 10 & 11 & KKEGKPCKP & 3.996 & Intermediate \\
\hline 11 & 40 & RCKLKLCLK & 3.844 & Intermediate \\
\hline 12 & 26 & DKDNKDHKK & 3.718 & Intermediate \\
\hline 13 & 42 & KLKLCLKF & 3.169 & Intermediate \\
\hline
\end{tabular}

